\title{
In situ photosynthetic quantum yield. Correspondence to hydrographic and optical variability within the Southern California Bight
}

\author{
Oscar Schofield ${ }^{1}$, Barbara B. Prézelin ${ }^{1}$, Robert R. Bidigare ${ }^{2}$, Raymond C. Smith ${ }^{3}$ \\ ${ }^{1}$ Department of Biological Sciences and Marine Science Institute, University of California, Santa Barbara, California 93106, USA \\ ${ }^{2}$ Department of Oceanography, 1000 Pope Road, Univeristy of Hawaii, Honolulu, Hawaii 96822, USA \\ ${ }^{3} \mathrm{CSL} / \mathrm{Center}$ for Remote Sensing and Environmental Optics, UCMBO and Geography Department, University of California, \\ Santa Barbara, California 93106, USA
}

\begin{abstract}
The Watercolors field study quantified time and space variability in the quantum yield for carbon fixation $(\phi)$ within the Southern California Bight, USA, (SCB) for 3 wk during summer 1988. The highly variable waters of the Bight allow a diverse spatial gradient in optical properties and phytoplankton community structure to be sampled on a single transect. Therefore this dataset provides a stringent test to any empirical model attempting to predict biological parameters. The data were used to determine whether observed variability in $\phi$ could be empirically explained by independent parameter(s) routinely measured at sea (e.g. nitrate, temperature, light, accessory pigmentation). Most of the phytoplankton communities sampled were light-limited and thus operating at a maximum quantum yield $\left(\phi_{\mathrm{max}}\right)$. In situ $\phi_{\mathrm{max}}$ values were routinely 2 - to 10 -fold lower than the theoretical upper limit of $0.125 \mathrm{~mol} \mathrm{C} \mu \mathrm{Ein}^{-1}$, varied more than 10 -fold over the time and space scales of the study, did not routinely increase with decreasing light levels, and showed no correlation with any single or set of environmental variables measured. These findings challenge existing assumptions regarding in situ behavior of $\phi$ as presented in many bio-optical models of primary production. The unpredictable behavior of $\phi$ was shown to result largely from variable correspondence between environmental parameters and the photosynthetic components of the quantum yield calculations, namely the photosynthesis-irradiance parameters $P_{\max } \alpha$ and $I_{k}$. The significance of these findings for bio-optical modeling of $\phi$ and primary productivity are discussed.
\end{abstract}

\section{INTRODUCTION}

Phytoplankton photosynthetic rates depend upon the efficiency with which absorbed light energy is converted to organic carbon. The measure of this efficiency is the operational quantum yield of carbon fixation $\left(\phi_{c}\right.$, mol C $\left.\mathrm{Ein}^{-1}\right)$, a term inherent in all absorption models which predict photosynthetic rates from the optical properties of the water column (Bidigare et al. 1992). Sensitivity analysis indicates that the estimation of $\phi_{c}$ is the most significant source of error in biooptical models of primary production (Smith et al. 1989) (for simplicity $\phi_{c}=\phi$ for the remainder of text). While the mathematical formulations of absorption-based models vary (Bidigare 1992), they all acknowledge that rates of photosynthesis are a direct function of the flux of photosynthetically available radiation $\left(Q_{\text {par }}\right)$, phytoplankton absorption capabilities $\left(a_{\mathrm{ph}}\right)$ and $\phi$ (Kirk 1983). Even production estimates based upon chlorophyll fluorescence measurements require estimates of $\phi$ for the eventual conversion to carbon fixation rates (cf. Falkowski \& Kiefer 1985, Kiefer et al. 1989).

The theoretical limit for the quantum yield of oxygen evolution $\left(\phi_{\mathrm{O}_{2}}\right)$ predicted by the Z-scheme of photosynthesis is 1 molecule $\mathrm{O}_{2}$ evolved per 8 quanta absorbed $(1 / 8=0.125)$. However, energy losses caused by Photoreaction I and non-perfect energy transfers yield an actual limit of about 0.10 (Myers 1980). This represents the upper limit for the quantum yield of carbon fixation; however the maximum quantum yield for carbon fixation $\left(\phi_{\max }\right)$ is often lower as it is dependent on the nitrogen source assimilated during photosynthesis 
(Myers 1980). The photosynthetic quotients (PQ) calculated by Laws (1991) can be used to estimate $\phi_{\max }$ for phytoplankton assimilating $\mathrm{NO}_{3}{ }^{-}(P Q=1.4), \mathrm{NO}_{3}{ }^{-}$and $\mathrm{NH}_{4}{ }^{+}(P Q=1.1)$ and $\mathrm{NH}_{4}{ }^{+}(P Q=1.1)$; these $P Q$ s translate into theoretical maximum carbon quantum yield values of $0.07,0.08,0.09 \mathrm{~mol} \mathrm{C} \mathrm{Ein}^{-1}$, respectively.

Some bio-optical models assume that $\phi$ for in situ phytoplankton communities is near this theoretical value. The maximum quantum yield ( $\phi_{\max }$ ) for photosynthesis is reached under light-limited conditions and an increasing number of field studies have shown that $\phi_{\max }$ is routinely lower than the theoretical maximum (Cleveland et al. 1989, Prézelin et al. 1991). When cells are light-limited for photosynthesis, $\phi$ equals $\phi_{\max }$. When photosynthesis becomes light-saturated or photoinhibited, $\phi$ values can fall significantly below those for $\phi_{\max }$. The suppression of $\phi$ values in bright light is thought to result largely from a $Q_{\text {par }}$-dependent reduction in the fraction of oxidized reaction centers 'open' for photosynthesis. This bright light suppression of $\phi$ is assumed to underlie field observations of depthdependent increases in $\phi$ (Tyler 1975, Dubinsky et al. 1984, Priscu 1984, Eppley \& Holm-Hansen 1986. Kishino et al. 1986). To accomodate this assumption, recent bio-optical models were revised to model $\phi$ as a depth-dependent parameter which approaches a constant $\phi_{\max }$ at low light levels (Kiefer \& Mitchell 1983, Bidigare et al. 1992).

Much uncertainty remains regarding the magnitude and spatial variability in $\phi$ as well as factors that might predictably regulate that variability. In the summer of 1988, a multidisciplinary cruise (Watercolors) was conducted in diverse waters off central California (USA) with aims (1) to generate a data base which quantified the variability in the quantum yield in California coastal waters on space scales of a few hundred kilometers and times scales of a few weeks, and (2) to employ this database to determine if any single or set of environmental variables (e.g. nitrate, temperature, light, and/or phytoplankton pigmentation) could account for most of the observed variablity for in situ $\phi$. The data enabled us to assess model assumptions regarding the behavior of $\phi$ in natural communities. Analyses of our field results strongly support prior findings which suggest that generalizations regarding $\phi_{\max }$ cannot be universally applied without significantly affecting the predictive accuracy of phytoplankton productivity models (Smith et al. 1989).

\section{MATERIALS AND METHODS}

Physical/chemical measurements and sample collection. During the Watercolors ' 88 cruise conducted in July-August 1988 aboard the RV 'Melville', repeated transects were made across a highly variable region of the Southern California Bight (SCB) (Schofield et al. 1991). A total of 129 vertical profiles of hydrographic and optical properties were completed along $250 \mathrm{~km}$ during 4 transects over a $3 \mathrm{wk}$ period. As previously described (Smith et al. 1990, Schofield et al. 1991), stations were sorted into groupings (A to L) which had similar hydrographic signatures (Fig. 1).

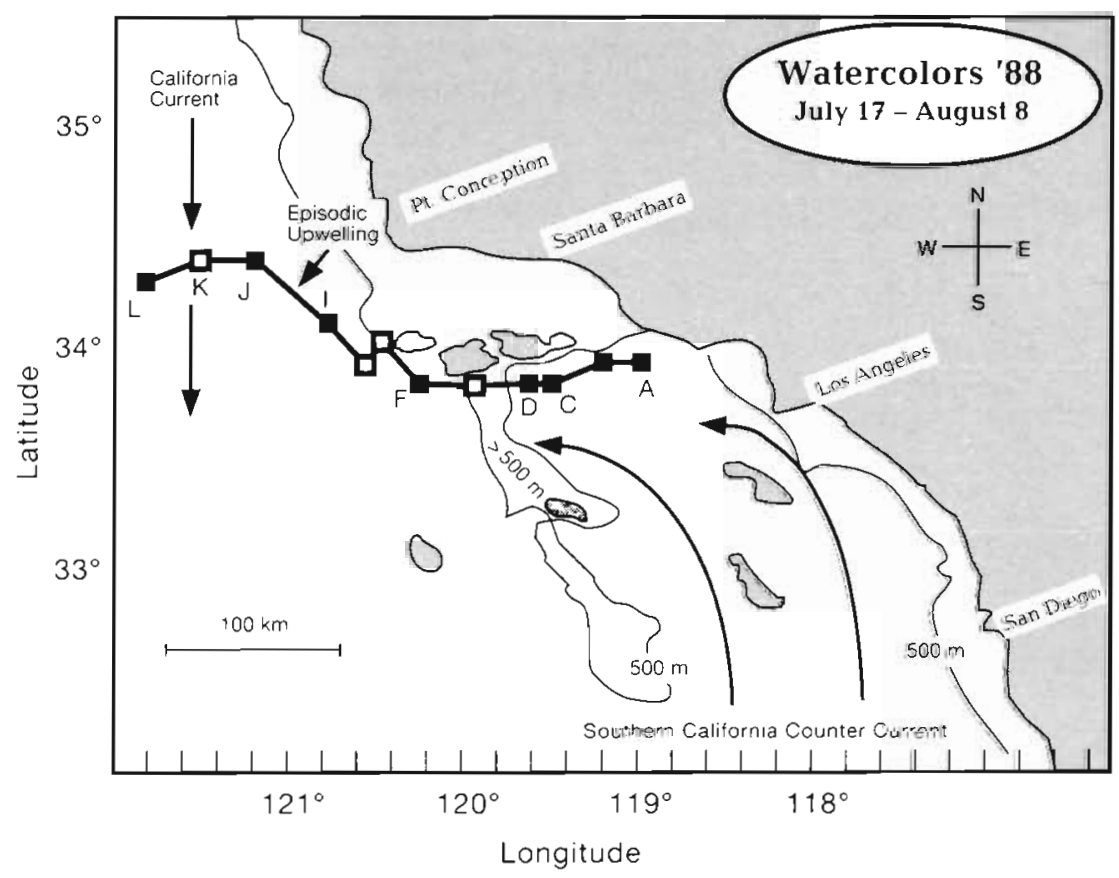

Fig. 1. Site of 12 transect locations (A to L) repeatedly sampled during the Watercolors cruise during $4 \mathrm{wk}$ in July and August 1988. Stations where a full array of biological data was collected are indicated by black squares. Major current systems encountered during the cruise are indicated by arrows 
A Bio-Optical Profiling System (BOPS; Smith et al. 1984) was used to determine the vertical structure of the water column and to collect seawater samples for chemical and biological analysis at each station (Schofield et al. 1991). Methods for chlorophyll a (chl a) and nitrate determinations $\left(\mathrm{NO}_{3}^{-}\right)$for discrete samples are described by Smith et al. (1987). Hydrographic features (e.g. density structure, chl, particle distributions, light fields, etc.) were identified during the downcast and confirmed on the upcast, at which time water samples were collected from discrete depths in 51 GoFlo bottles for shipboard studies.

Biological measurements. A total of 64 biological data sets were analyzed in the present study, each containing complete information on HPLC-determined phytoplankton pigmentation and photosynthesisirradiance (P-I) parameters in addition to physical, chemical and optical data acquired concurrently for the same sampling depth. This database met the added criterion that all measured variables within a given data set had standard error estimates $<50 \%$. All samples were collected during daylight hours and largely during duplicate transects (east to west on July 23 and west to east on August 2). No attempt was made to normalize data sets to a single time of day. While diel variations in photosynthetic parameters are commonly observed in natural communities (Prézelin et al. 1991) and time corrections are possible (Smith et al. 1989, Prezelin \& Glover 1991. Schofield et al. 1991), the objectives of the present study were to assess the instantaneous relationship between quantum yield and major environmental parameters and to determine whether traditional sampling methods could be used to estimate quantum yield from knowledge of hydrographic and/or optical properties. The data are presented in contours to provide a simple spatial context in which to discuss the results.

Phytoplankton pigmentation and phytoplankton absorption. Reverse-phase high performance liquid chromatography was used to separate and quantify phytoplankton chlorophylls (chl $a_{1}, \mathrm{chl} b, \mathrm{chl} c_{1}+c_{2}+c_{3}$ ) and carotenoids (peridinin, prasinoxanthin, zeaxanthin, diadinoxanthin, diatinoxanthin, fucoxanthin, 19'-hexanoyloxy-fucoxanthin, and 19'-butanoyloxyfucoxanthin) in discrete samples (Bidigare et al. 1990). Phycobilin pigment analyses were limited to a small subset of samples. There was an indication that phycoerythrin-rich phytoplankton were detectable within the Southern California Bight (Bidigare \& Ondrusek 1989). However, measurements of whole cell detritalcorrected absorption spectra indicated that phycobilins were never significant contributors to the total lightharvesting capabilities of the mixed phytoplankton communities sampled during the present study (Schofield et al. 1991).
About $25 \%$ of the data sets analyzed in the present study also included direct spectral measurements of resuspended particle absorption $\left[a_{p}(\lambda)\right]$ (Bidigare et al. 1990, Schofield et al. 1991, Nelson et al. unpubl.). These spectra were corrected for estimates of detrital absorption $\left[a_{d}(\lambda)\right]$ in order to provide a spectral estimate of phytoplankton community absorption $\left[a_{\mu h}(\lambda)\right.$ $\left.=a_{p}(\lambda)-a_{d}(\lambda)\right]$ (Schofield et al. 1991). To estimate phytoplankton spectral absorption with the entire data base, we used the alternative approach of spectral reconstruction of phytoplankton absorption from knowledge of HPLC pigmentation measured within discrete samples (Bidigare et al. 1992). This approach assumes no pigment packaging effects and that all photosynthetic pigments are resolved by HPLC analyses (Bidigare et al. 1990). Volumetric spectral absorption capabilities $\left[a_{\mathrm{ph}}{ }^{\prime}(\lambda), \mathrm{m}^{-1}\right]$ were calculated as a summation of the products in vivo absorption coefficients $\left[a_{i}^{*}(\lambda), \mathrm{m}^{2} \mathrm{mg}^{-1}\right]$ and volume-based concentrations $\left(c_{1}, \mathrm{mg} \mathrm{m}^{-3}\right)$ of individual chlorophyll and carotenoid pigments within discrete samples (Bidigare et al. 1990).

$$
a_{\mathrm{ph}}{ }^{\prime}(\lambda, z)=\sum_{l=1}^{\mathrm{n}} c_{i}(z) \cdot a_{i} \cdot(\lambda)
$$

To estimate in situ quantum yield from photosynthesis-irradiance (P-I) curves, it is necessary to calculate the spectrally-weighted absorption coefficient $\left.(\bar{a})_{p h}, \mathrm{~m}^{-1}\right)$ for each in situ phytoplankton community. To do so, the spectral properties of photosynthetically available radiation $\left(Q_{\text {par }}\right)$ at the sampling depth $z$ are required and were here determined from measured spectral downwelling irradiance $\left[Q_{d}(\lambda, z)\right.$, $\mu$ Ein $\mathrm{m}^{-2} \mathrm{~s}^{-1} \mathrm{~nm}^{-1}$ ] (Smith et al. 1987). The spectrallyweighted absorption coefficient was calculated according to (Smith et al. 1987):

$$
(\bar{\alpha})_{\mathrm{ph}}{ }^{\prime}=\frac{\int_{400}^{700} a_{\mathrm{ph}}{ }^{\prime}(\lambda, z) \cdot Q_{\mathrm{d}}(\lambda, z) \mathrm{d} \lambda}{\int_{400}^{700} Q_{\mathrm{d}}(\lambda, z) \mathrm{d} \lambda}
$$

An estimate of the amount of spectral irradiance absorbed in situ by discrete phytoplankton communities $\left[A Q_{\mathrm{ph}}(\lambda), \mu\right.$ Ein $\left.\mathrm{m}^{-3} \mathrm{~s}^{-1} \mathrm{~nm}^{-1}\right]$ was calculated here as the product of $a_{p h^{\prime}}(\lambda)$ and $Q_{d}(\lambda)$ (Smith et al. 1989). Integrating $A Q_{p h}(\lambda)$ over the visible spectrum yields an estimate of the total quanta absorbed $\left(A Q_{\mathrm{ph}}\right)$, e.g.

$$
A Q_{\mathrm{ph}}=\int_{400}^{700} a_{\mathrm{ph}}{ }^{\prime}(\lambda, z) \cdot Q_{\mathrm{d}}(\lambda) \mathrm{d} \lambda
$$

Photosynthetic parameters. Short-term (2 h) shipboard ${ }^{14} \mathrm{C}$-incubations of whole water samples were made to determine 'instantaneous' photosynthesisirradiance (P-I) relationships of $\geq 0.4 \mu \mathrm{m}$ phytoplankton 
communities. Up to 8 discrete depths were sampled at each station and samples were incubated at the in situ temperature and over a range of white light intensities. The procedures of sample collection, preparation, incubation and radiolabel uptake determinations have been described previously (Prézelin et al. 1989). Nonlinear curve fits for P-I data were calculated using the simplex method of Caceci \& Cacheris (1984). Curve fitting procedures provided estimates of $P_{\max }$ (the lightsaturated rate of photosynthesis), $\alpha$ (the light-limited rate of photosynthesis) and $I_{k}=P_{\text {max }} / \alpha$ (an estimate of the minimum irradiance required to light-saturate rates of photosynthesis). In situ photosynthetic rates were calculated as a hyperbolic tangent (Platt \& Gallegos 1980), in part due to the earlier findings of Jassby \& Platt (1976) that showed that the hyperbolic tangent function provided the best fit to a large $(n=$ 188 in duplicate) database of P-I relationships. Thus,

$$
P(z)=P_{\max }(z) \cdot \tanh \left[\frac{Q_{p a r}(z)}{I_{k}(z)}\right]
$$

where $Q_{\text {par }}(z)$ is the in situ irradiance. Estimates of the standard deviations for the P-I parameters were calculated using the procedures described by Zimmerman et al. (1987). It has been demonstrated that white light can lead to a spectral bias (Schofield et al. 1991) and therefore our measurements represent lower limit estimates especially at depth; however as this study is interested in the dynamic nature of these parameters the overall analysis is still valid.

Maximum and operational quantum yield. Estimates of the maximum quantum yield $\left[\phi_{\max }(z)\right]$ were calculated by dividing the $\alpha(z)$ by $(\bar{a})_{p h}{ }^{\prime}(z)$, e.g.

$$
\phi_{\max }(z)=\frac{\alpha(z)}{\bar{a}_{p h}{ }^{1}(z)}
$$

Our estimates of the operational quantum yield $[\phi(z)]$ were calculated by dividing the in situ photosynthetic rate $P(z)$ by the total quanta absorbed by phytoplankton $A Q_{\text {ph }}{ }^{\prime}(z)$, e.g.

$$
\phi(z)=\frac{P(z)}{A Q_{\mathrm{ph}^{\prime}}(z)}=\frac{P_{\max }(z)}{A Q_{\mathrm{ph}}{ }^{\prime}(z)} \cdot \tanh \left[\frac{Q_{\mathrm{par}}(z)}{I_{k}(z)}\right]
$$

Given our estimate of $P(z)$ is based upon Eq. 4, we based our estimate of in situ $\phi(z)$ upon a hyperbolic tangent relationship defined for P-I parameters. This eliminated the mathematical discrepancy between production calculated from a P-I curve and models which estimate $\phi(z)$ with a rectangular hyperbola (Bidigare et al. 1992). A distinction between our hyperbolic tangent formulation for $\phi(z)$ and that of Bidigare et al. (1992) is that Eq. 6 requires no estimate of $\phi_{\operatorname{mox}}$ but only an estimate of $P_{\max }$ and $I_{k}$

Linear regression analyses were based upon volumebased estimates of the 4 dependent variables $\phi(z)$,
$P_{\text {max }}(z), \alpha(z)$, and $I_{k}(z)$ and a group of 6 independent environmental variables. The 6 input parameters for regression analyses included $Q_{\text {par }}(z)$ lor $\% Q_{\text {par }}(z)$ to remove any diurnal variation in $Q_{\text {par }}(z)$ ), water temperature, concentration of inorganic nitrate, chl $a$, total photosynthetic carotenoids $\left(\mathrm{psc}=\right.$ fucoxanthin $+19^{\prime}$ hexanoyloxy-fucoxanthin $+19^{\prime}$ - butanoyloxyfucoxanthin + peridinin), and total photoprotective carotenoids $(\mathrm{ppc}=$ zeaxanthin + diadinoxanthin + diatinoxanthin + prasinoxanthin). The Systat module MGLH (Systat Inc., Glenview, IL, USA) and the Microsoft Excel 3.0 LINEST function (Microsoft Inc., Redmond, WA, USA) were both used for the regression analyses. Backward stepwise regression was used to delineate the most significant independent variables within the multiple linear regressions. Dependent variables were then individually regressed again but only against the most significant input parmeters. This was done to determine the degree to which the most significant input parameters could explain the temporal and spatial variability for $\phi(z)$, $P_{\max }(z), \alpha(z)$, and $I_{k}(z)$. In addition, input parameters were alternately tested as nontransformed, log, and natural log transformed variables. Similar analyses were repeated when ppc concentrations were removed from $\phi$ calculations, where ppc had previously been part of the $a_{p h}$ ' estimates.

\section{RESULTS}

\section{Variablity of hydrographic and phytoplankton input parameters}

During the Watercolors cruise, 4 hydrographic transects of the northern section of the Southern California Bight (SCB) were completed during July-August 1988 (Fig. 1). Analyses of the physical charactertistics of 129 BOPS profiles (Smith et al, 1990, Baker \& Smith pers. comm.) indicated that the transect line crossed variable water masses (Stns A to L). Hydrographic differences were attributed to the California Current (CC) flowing from the north, the Southern California Counter Current (SCCC) flowing from the south and upwelled waters flowing west/southwestward from Point Conception (Smith et al. 1990, Baker \& Smith pers. comm.).

The present study focused on a subset $(n=64)$ of the total ( $\mathrm{n}=232$ ) Watercolors P-I measurements that met criteria of being only short-term $(<2$ h) measurements on freshly collected in situ samples (e.g. no samples from deckboard diurnal studies), being accompanied by complete knowledge of the 6 independent input variables required for regression analyses. This 'quantum yield' database was collected largely during 2 biological transects on July 23 and August 2. The 
majority of data $(n=53)$ in this database were collected for Stns A to I which spanned about $150 \mathrm{~km}$ of the SCB (Fig. 1). Stns A to D had hydrographic signatures clearly attributable to SCCC waters (Smith et al. 1990, Baker \& Smith pers comm.). Although Stn F was separated from Stns A to D by a topographical plateau, it also had a hydrographic signature mostly attributable to SCCC. Stn I, situated at a deeper water location on the Continental Shelf Break, appeared to be a transition station between the water masses but with a strong affinity with waters of the SCCC. The other 11 datasets were collected during one depth profile of upwelled waters off Pt. Conception at Stn. J on July 28 and one depth profile of CC waters at Stn L on July 30.

A mesoscale view of the temporal/spatial variability in light depth ( 1 and $10 \% Q_{\text {par }}$ ), temperature $\left({ }^{\circ} \mathrm{C}\right)$ and nitrate $(\mu \mathrm{M})$ at Stns $\mathrm{A}$ to J during 4 Watercolors transects is presented in Fig. 2. On July 23 and 24, there was about a $6{ }^{\circ} \mathrm{C}$ gradient in surface temperature between the east end of the transect (Stn C) and the cooler waters (Stns I \& J) over the Continental Shelf (Fig. 2, top). Chl a patterns indicated that plant biomass was concentrated in subsurface maxima at the $10 \%$ light depth (Fig. 3a) which was slightly above the nitracline (Fig. 2, bottom) (see also Schofield et al. 1991).

On July 23 the SCCC waters were characterized by mixed populations of phytoplankton. Green algae (prochlorphytes, prasinophytes, chlorophytes), as characterized by chl $b$ distribution (Fig. 3c), were concentrated in the center of the transect and within the chl a maximum at the eastern end of the transect. Photosynthetic prokaryotes (prochlorophytes and/or cyanobacteria), characterized by the distribution of zeaxanthin (Fig. 3k), were most abundant at the west end of the transect. Highest plant biomass was measured in the chl a maximum at Stn I (Fig. 3a). It was dominated by diatoms, as characterized by the fucoxanthin distribution (Fig. 3g; Schofield et al. 1991). Prymnesiophytes were also present in significant but lesser amounts, as indicated by the distribution of hex-fucoxanthin (Fig. 3i).

Between the time of the 2 biological transects, data were collected in postupwelled waters off $\mathrm{Pt}$. Conception (Stn J) and the California Current west of Pt. Conception (Stn L). At the time of sampling, diatoms dominated the upwelled waters with lesser amounts of other chromophytic phytoplankton present. The reverse was true at $\mathrm{Stn} \mathrm{L}$ where hex-fucoxanthin was several-fold higher than any other accessory pigment (Bidigare \& Ondrusek 1989, Sloan \& Bidigare 1990).

By the first week of August, hydrographic data indicated that the intrusion of upwelled waters across the transect line lessened (Fig. 2), presumably due to a relaxation of upwelling winds of $\mathrm{Pt}$. Conception (Smith et al. 1990, Baker \& Smith unpubl.). Consistent with this view was our observation of a reduction in the surface temperature gradient between Stns A to I (Fig. 2, top) and a $>3$-fold decline in fucoxanthin concentration (Fig. 3g, h). Hex-fucoxanthin (Fig. 3i, j), which had been previously concentrated at the west end of the transect, became the dominant accessory carotenoid throughout the SCB. Hex-fucoxanthin was most evident as a subsurface maximum centered near the $10 \%$ light depth (Fig. 2, top). Chlorophyll b (Fig. 3c, d), which had been previously associated with SCCC waters, became more abundant throughout surface waters of the SCB. A more detailed time-series analysis of pigment distribution during Watercolors ' 88 can be found elsewhere (Bidigare \& Ondrusek 1989).

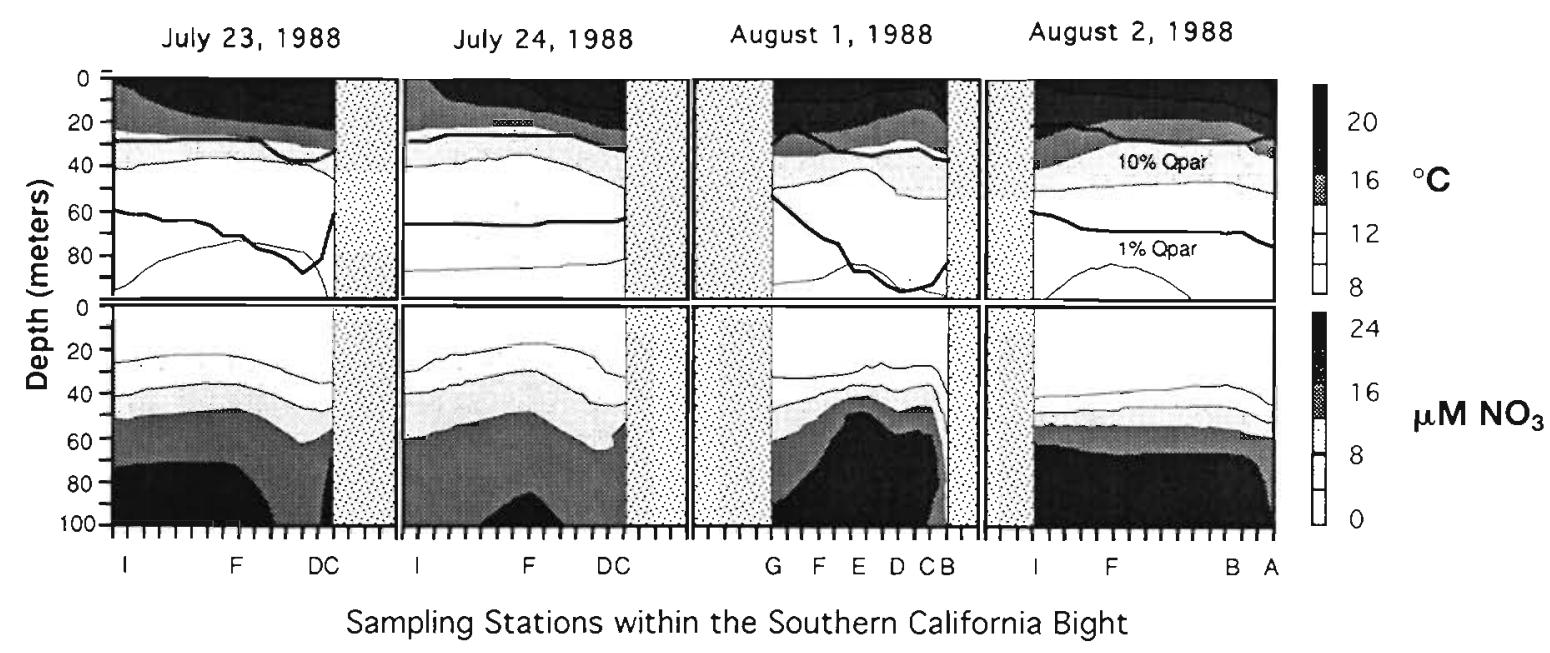

Fig. 2. Spatial contours for temperature $\left({ }^{\circ} \mathrm{C}\right)$ and inorganic nitrate $(\mu \mathrm{M})$ for 4 transects of the Southern California Counter Current (SCCC) conducted during July and August during Watercolors '88. Stippled areas indicate areas which were not sampled. The 10 and $1 \%$ light depths are denoted by black lines on the temperature contour 


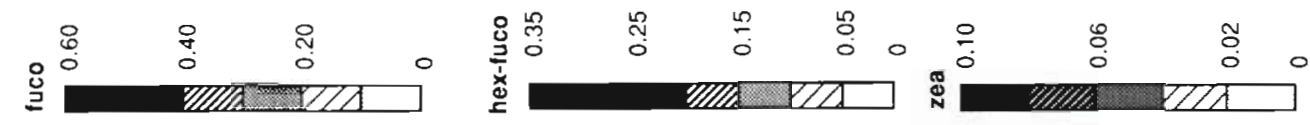

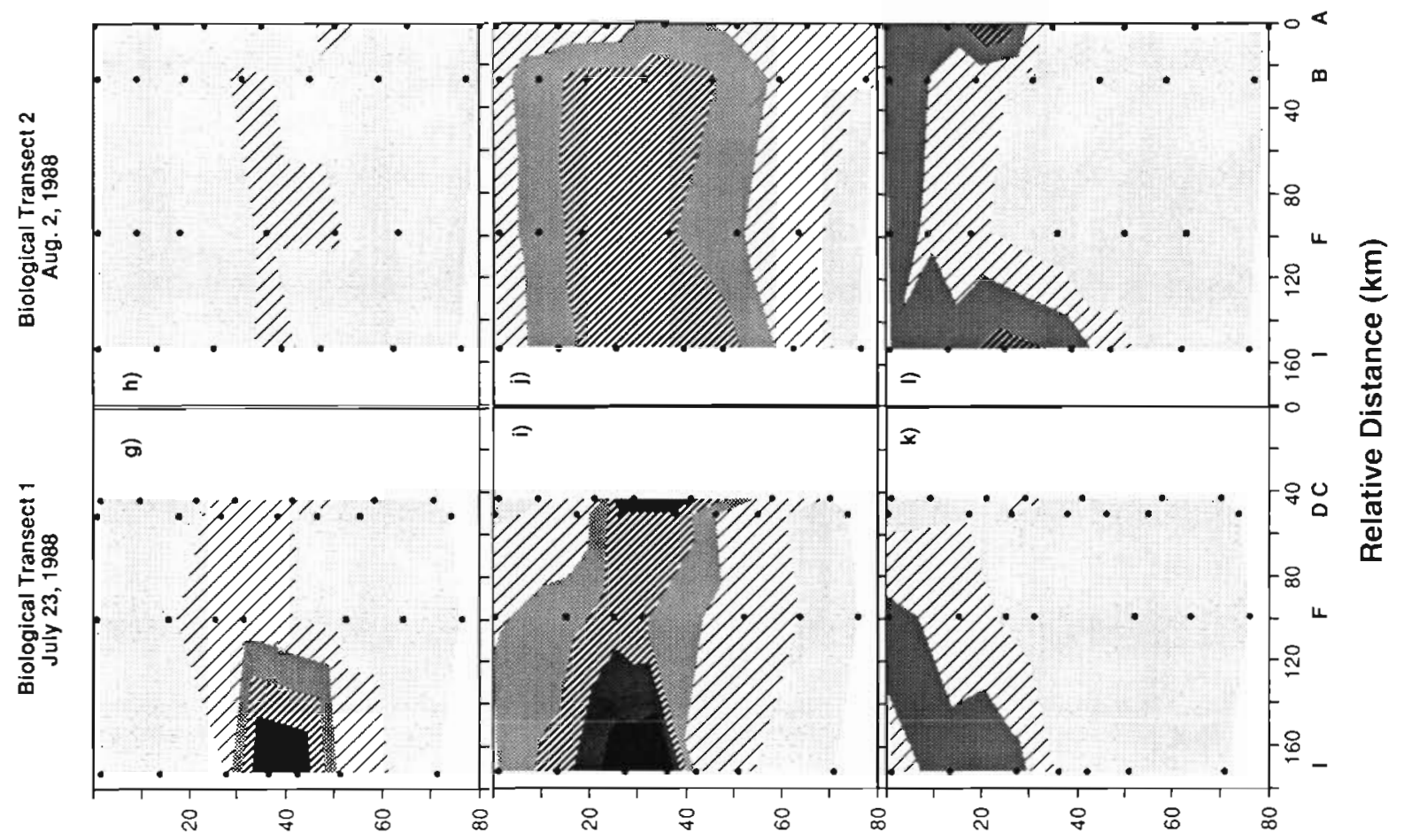

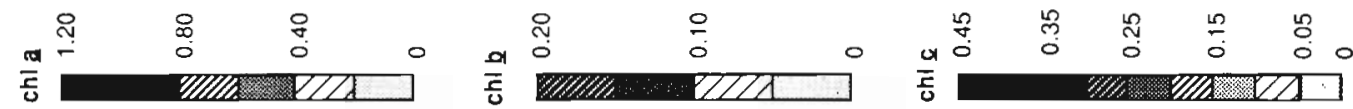

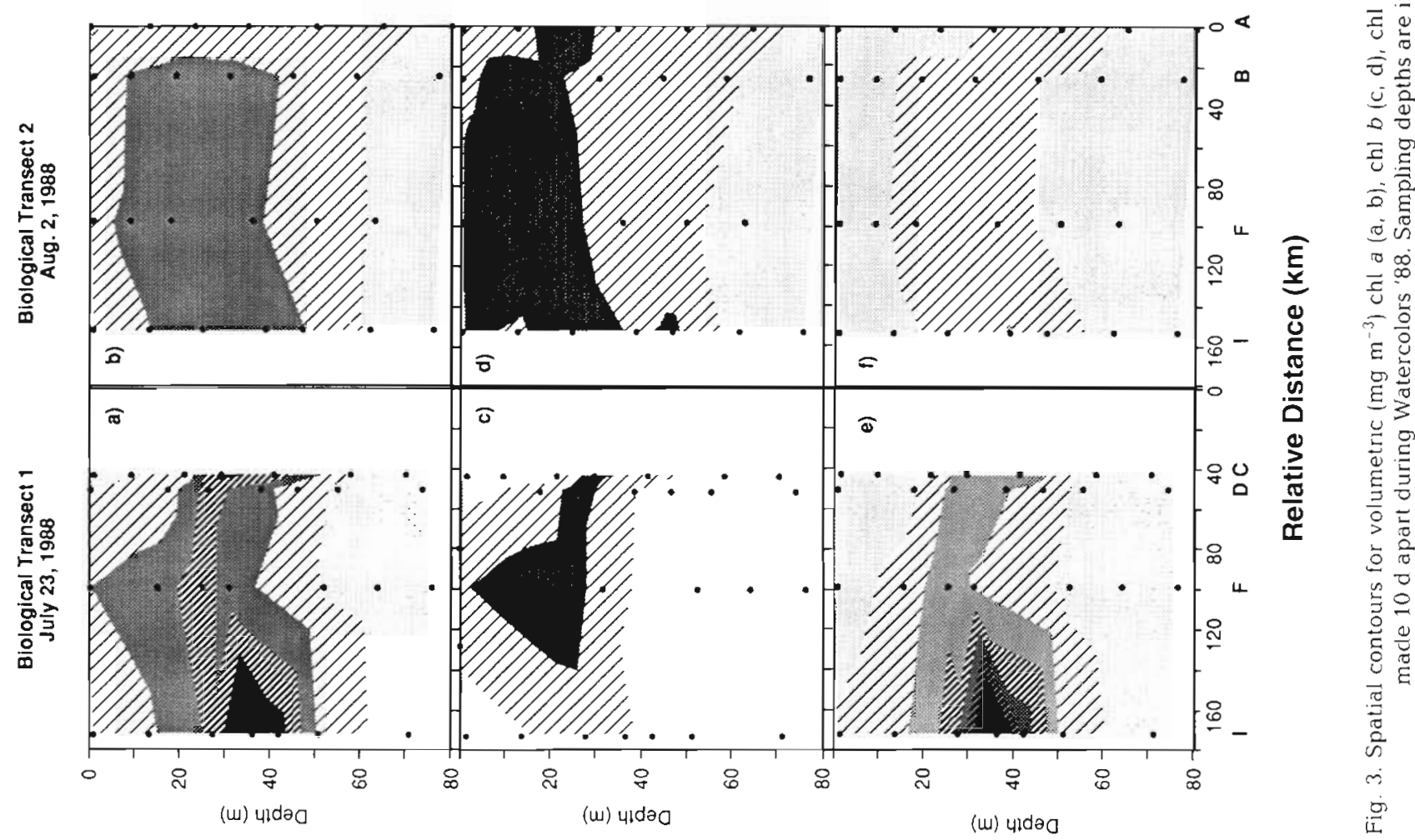




\section{Variability of quantum yield and photosynthetic parameters}

In Fig. 4 the depth-dependent profiles of the chl-specific estimates of $P_{\max }$ and $\alpha$ for 2 transects within the SCCC are compared to samples collected within the $\mathrm{CC}$ and post-upwelled waters. On the July 23 transect chl-specific P-I parameters were consistently low and showed little depth-dependence. In contrast to the July 23 transect the CC, post-upwelled waters from off Pt. Conception, and August 2 transect all showed distinct subsurface maxima. Subsurface maxima in $P_{\max }$ chl $a^{-1}$ were consistently above the $10 \%$ light depth with highest values observed during Transect 2 on August 2. The depth of the subsurface maxima for $\alpha$ chl $a^{-1}$ varied with each profile which probably reflected changes in both community composition and photoadpative state. As with $P_{\max }$ chl $a^{-1}$, highest $\alpha$ chl $a^{-1}$ values were observed during the August 2 transect of the SCCC. In general $P_{\max } \mathrm{chl} \mathrm{a}^{-1}$ and $\alpha$ chl $a^{-1}$ covaried $\left(p<0.01, R^{2}=0.37\right)$, which resulted in $I_{k}$ always decreasing with depth (Fig. 4c). The decreasing $I_{k}$ values with depth were relatively stable over the cruise (Fig. 4c).

Some evaluation of the environmental regulation and photophysiological consequences of these and other photosynthetic changes documented during Watercolors ' 88 have been presented elsewhere (Prézelin et al. 1991, Schofield et al. 1991, Bidigare et al. 1992). Here it is sufficient to note the variability observed in P-I parameters and that, in addition to a shift in the hydrographic features within the SCB between the time of the 2 biological transects (physical transects support the view that there were significant changes in the hydrographic properties), there were significant photophysiological changes within the phytoplankton communities that remained in the SCB. For instance, chl-specific $P_{\max }$ and $\alpha$ increased very noticeably in the SCB between July 23 and the first week of August (Fig. 4). Such large increases in production parameters, es-
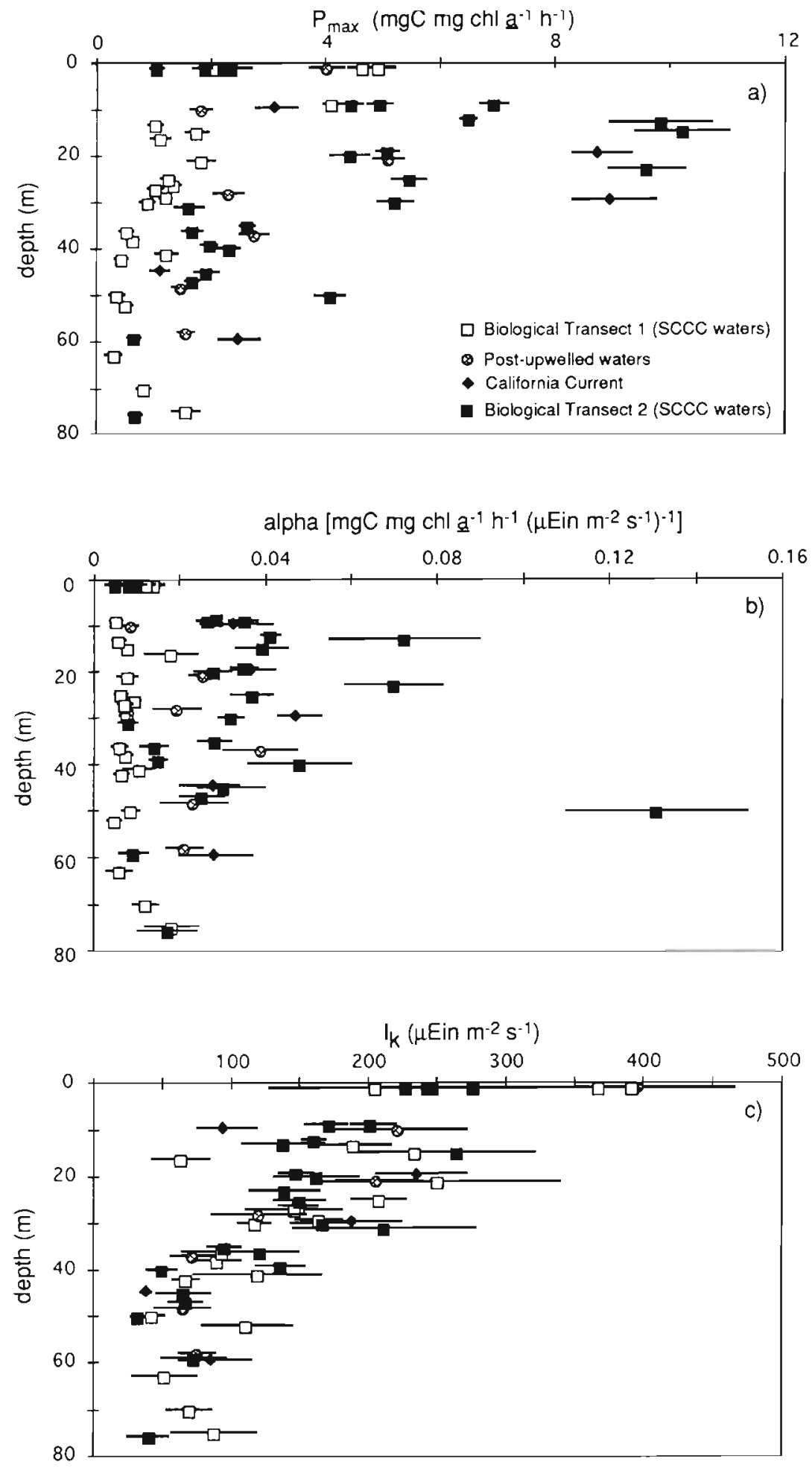

Fig. 4. Depth profiles for (a) the chl-specific maximum photosynthetic rate ( $P_{\max }$, mgC mgchl $a^{-1} h^{-1}$ ), (b) the chl-specific light-limited slope of photosynthesis $[\alpha$, mgC mgchl $\left.a^{-1} h^{-1}\left(\mu \text { Ein } \mathrm{m}^{-2} s^{-1}\right)^{-1}\right]$ and (c) the irradiance at which photosynthesis is light-saturated $\left(\mathrm{P}_{\max } / \alpha, \mu \operatorname{Ein} \mathrm{m}^{-2} \mathrm{~s}^{-1}\right)$ for 2 transects of the SCCC $(\square, \boldsymbol{\square})$, the CC $(\bullet)$, and post-upwelled waters $(\bullet)$. The standard deviations for the P-I parameters were calculated following the procedures of Zimmerman et al. (1987) and denoted by black lines 
pecially within the chl a maximum communities (Fig. 3), could be attributable to accelerted growth and/or photoadaptation by resident populations of phytoplankton.

Phytoplankton absorption spectra had to be determined in order to derive estimates of operational ( $\phi$; Eq. 6) and maximum quantum yield ( $\phi_{\max } i$ Eq. 5). Onefourth of our quantum yield database included directly measured detrital-corrected phytoplankton absorption $\left(a_{p h}\right)$ (Schofield et al. 1991) while the entire dataset included HPLC pigmentation. It is important to note that both approaches used to estimate phytoplankton absorption spectra were independent of one another. Fig. 5 provides a comparison of these independent estimates of $a_{\mathrm{ph}}(675 \mathrm{~nm})$ and $a_{\mathrm{ph}}{ }^{\prime}(675 \mathrm{~nm})$. The correspondance between $a_{p h}$ and $a_{p h}$ ' was significant ( $\mathrm{p} \ll 0.01, \mathrm{R}^{2}=0.81$ ) with a standard error of $8 \%$. Detailed analyses of $a_{p h} v s a_{p h}$ measurements for the larger Watercolors database will be presented elsewhere (Nelson et al. unpubl.). Those results suggest that much of the discrepancy between $a_{\mathrm{ph}} \mathrm{vs} a_{\mathrm{ph}}{ }^{\prime}$ was attributable to systematic error in both procedures. Deviations from a 1:1 correspondence between $a_{p h}$ and $a_{p h}$ ' might be attributed to either (1) errors in detrital absorption corrections for $a_{\text {ph, }}$ (2) 'missing pigments' not resolved by HPLC analyses (e.g. phycobilins), and/or (3) 'pigment packaging' effects (see Kirk 1983, Morel \& Bricaud 1986). The effect that each of these discrepancies would have on the direction of change in the correspondance between $a_{\mathrm{ph}} \mathrm{vs} a_{\mathrm{ph}}$ ' is indicated in Fig. 5. While further study may lead to refinements in our estimates of both $a_{\mathrm{ph}}$ and $a_{\mathrm{ph}}$, the relative changes in the P-I parameters were much larger than the error associated with using $a_{p h}{ }^{\prime}$ to calculate $\phi$.
Time/space contour plots for $\phi$ in the SCB are shown in Fig. 6 and the correspondence between $\phi$ and $\phi_{\max }$ is illustrated in Fig. 7. The correspondence between $\phi$ and $\phi_{\max }$ is a useful index of light-limitation. Only in the surface was $\phi \neq \phi_{\max }$. Below the surface, the phytoplankton were generally light-limited for photosynthesis and $\phi=$ $\phi_{\max }$. Furthermore deckboard diurnal studies indicated that light-saturation was reached for subsurface samples at depths of $<10 \mathrm{~m}$ for a short period around solar noon (Boucher et al. 1990, Prézelin et al. 1991). Thus, the variability for $\phi$ (Fig. 6) also describes the pattern of natural variability in $\phi_{\max }$ for all subsurface samples.

In situ $\phi_{\max }\left(\mathrm{mol} \mathrm{C} \mathrm{Ein}^{-1}\right.$ ) values were routinely 2 - to 10 -fold lower than the theoretical upper limit of $0.125 \mathrm{~mol} \mathrm{C} \mathrm{Ein}^{-1}$, varied more than 10 -fold over the time and space scales of the study, and did not routinely increase with decreasing optical depth. On the July 23 transect, $\phi$ values never exceeded $0.03 \mathrm{~mol} \mathrm{C} \mathrm{Ein}^{-1}$ and highest values for $\phi$ tended to be at the east end of the transect line and at the base of the euphotic zone near the $1 \%$ light depth. In contrast, $\phi$ values approached $0.06 \mathrm{~mol} \mathrm{C} \mathrm{Ein}^{-1}$ during the first week of August (Fig. 6). Highest values for $\phi$ were associated with the subsurface chl max (Fig 3a) at or above the $10 \%$ light depth (Fig. 2, top) which was dominated by green algae (Fig. 3d). A secondary peak in $\phi$ values was detectable at about $50 \mathrm{~m}$ (Fig. 6) around the $5 \%$ light depth (Fig. 2). Quantum yield values were also high in the colder nutrient-rich waters to the north. At both Stns J and L there was subsurface maxima in $\phi$ which was associated with the nitracline. Within this subsurface maxima $\phi$ values were 0.05 and 0.07 for Stns $\mathrm{J}$ and L respectively (data not presented)

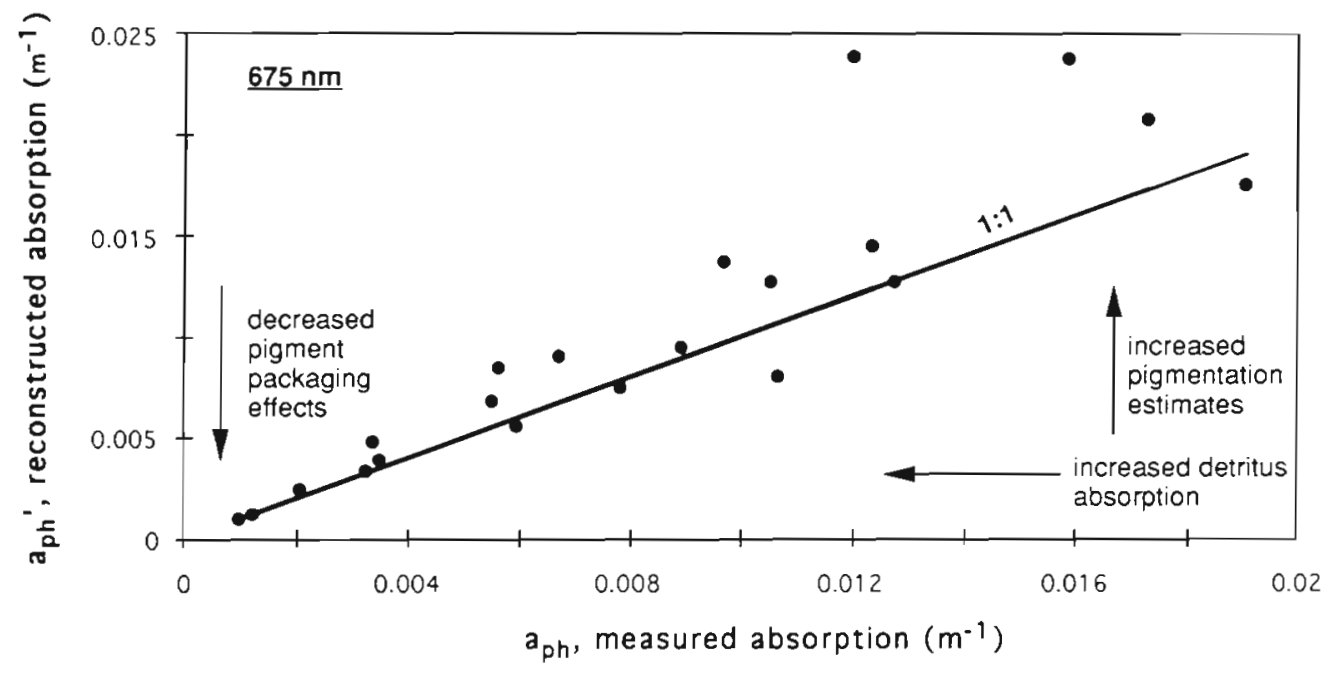

Fig. 5. Comparison of measured detrital-corrected phytoplankton absorption $\left(a_{\mathrm{ph}} \mathrm{m}^{-1}\right)$ and absorption reconstructed from phytoplankton pigmentation $\left(a_{\mathrm{ph}} \mathrm{h}^{\prime} \mathrm{m}^{-1}\right)$ at $675 \mathrm{~nm}$ during Watercolors '88. A significant linear relationship $\left[1.19\left(a_{\mathrm{ph}}{ }^{\prime}\right)+5.8 \times 10^{-5}\right.$. $R^{2}=0.81$ ] was present $(p \ll 0.01)$. The bold line denotes a $1: 1$ relationship with detrital-corrected absorption. The relative impact of missing pigments not included in the absorption reconstructions, pigment packaging effects, and under-estimated detritus absorption is denoted by black arrows 


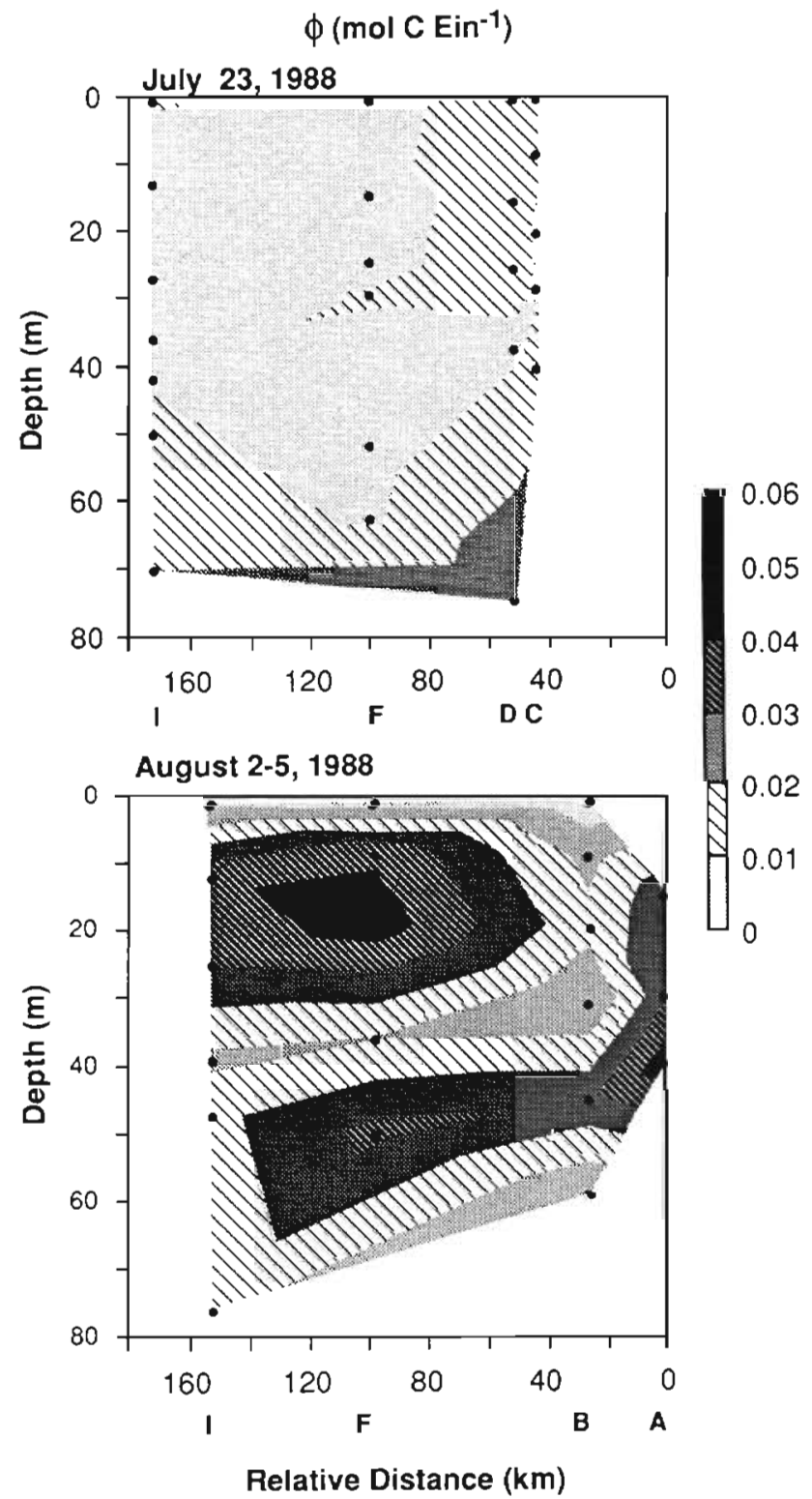

Fig. 6. Spatial contours for the operational quantum yield ( $\phi$; mol C Ein ${ }^{-1}$ ) during 2 transects of the SCCC during Watercolors ' 88 . Blological Transect 1 was conducted from dawn to dusk on July 23, 1988. Biological Transect 2 was conducted from dawn to dusk on August 2, 1988 with exception of Stn A where data was collected on August 5. Sampling depths are indrcated by black crrcles; white areas indicate regions which were not sampled

\section{Regression anlayses of time/space variability in in situ quantum yield}

Regression analysis of the maximum and operational quantum yield is presented in Table 1. Significant regressions were obtained for $\phi$ and $\phi_{\max }$ when the entire data set (SCCC + upwelling profile $+\mathrm{CC}$ profile) or the SCCC data subset alone was analyzed.

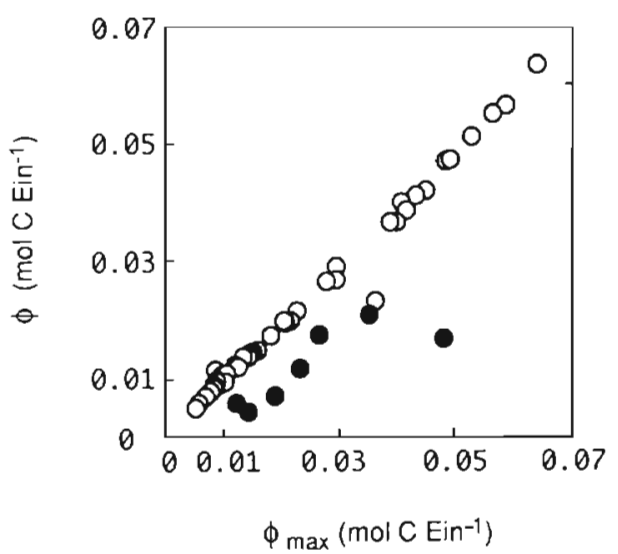

Fig. 7. Comparison of the operational ( $\phi ; \mathrm{mol} \mathrm{C} \mathrm{Ein}^{-1}$ ) and maximum quantum yield ( $\phi_{\max } \mathrm{mol} \mathrm{C} \mathrm{Ein}^{-1}$ ) during Watercolors '88. (-) Surface waters and near surface waters $(z<10 \mathrm{~m})$ at local noon; $(0)$ all other depths

However, the low $\mathrm{R}^{2}$ values indicated that the regressions had little predictive value. No input parameter was a significant correlant to the variability of quantum yield.

When the entire quantum yield database or SCCC subset was analyzed, highly significant regressions $(p<0.001)$ for $P_{\max }$ were resolved (Table 1). However, the most significant input parameters varied depending which subset of the database was being analyzed. For the entire database, variability in $P_{\max }$ was negatively correlated to nitrate concentrations and positively correlated to temperature. Together, these 2 parameters could account for $30 \%$ of the observed variability in $P_{\max }$. When the SCCC database alone was analyzed, variability in $P_{\max }$ was no longer correlated to nitrate availability but was still positively correlated with temperature. In addition, $P_{\max }$ in the SCCC database was negatively correlated with $\% Q_{\text {par }}$. Within the SCCC, temperature and $\% Q_{\text {par }}$ could account for $41 \%$ of the observed variability in $P_{\max }$.

When the entire database was analyzed, significant regressions for $\alpha$ were obtained using all input parameters. Chl a was the most significant input parameter and accounted for $19 \%$ of the observed variability in $\alpha$. Within the SCCC database, $39 \%$ of the variability in $\alpha$ could be inversely linked to variability in temperature, $\% Q_{\text {par }}$, and the abundance of photoprotective carotenoids.

Most interesting was the highly significant correlation between $I_{k}\left(=P_{\max } / \alpha\right)$ and $\% Q_{\text {par }}$. While perhaps reflective of the highly stratified nature of the SCCC at the time of the Watercolors cruise (Lewis pers. comm.), it was shown that the regression was still highly significant whether or not data from the more turbulently mixed upwelled waters and the $\mathrm{CC}$ were included 
Table 1. Multiple linear regression analysis for the quantum yield for carbon fixation (maximum $\left[\phi_{\max } \mid\right.$ and operational [ $\left.\phi\right]$ ] lightsaturated rate of photosynthesis $\left(P_{\text {maxi }} \mathrm{mg} \mathrm{C} \mathrm{m}^{-3} \mathrm{~h}^{-1}\right)$, the light-limited slope for photosynthesis $\left[\alpha, \mathrm{mg} \mathrm{C} \mathrm{m}^{-3} \mathrm{~h}^{-1}\left\langle\mu \mathrm{Ein} \mathrm{m}^{-2} \mathrm{~s}^{-1}\right)^{-1}\right]$ and the light saturation parameter $\left(I_{k}, \mu \mathrm{Ein}^{-2} \mathrm{~s}^{-1}\right)$. Backward stepwise regression was used to delineate which independent variables were of greatest significance for the multiple linear regressions. $(+)$ and (-) symbols denote a positive and negative correlation for

the most significant parameters. Only the most significant parameters were used in a second set of multiple linear regressions

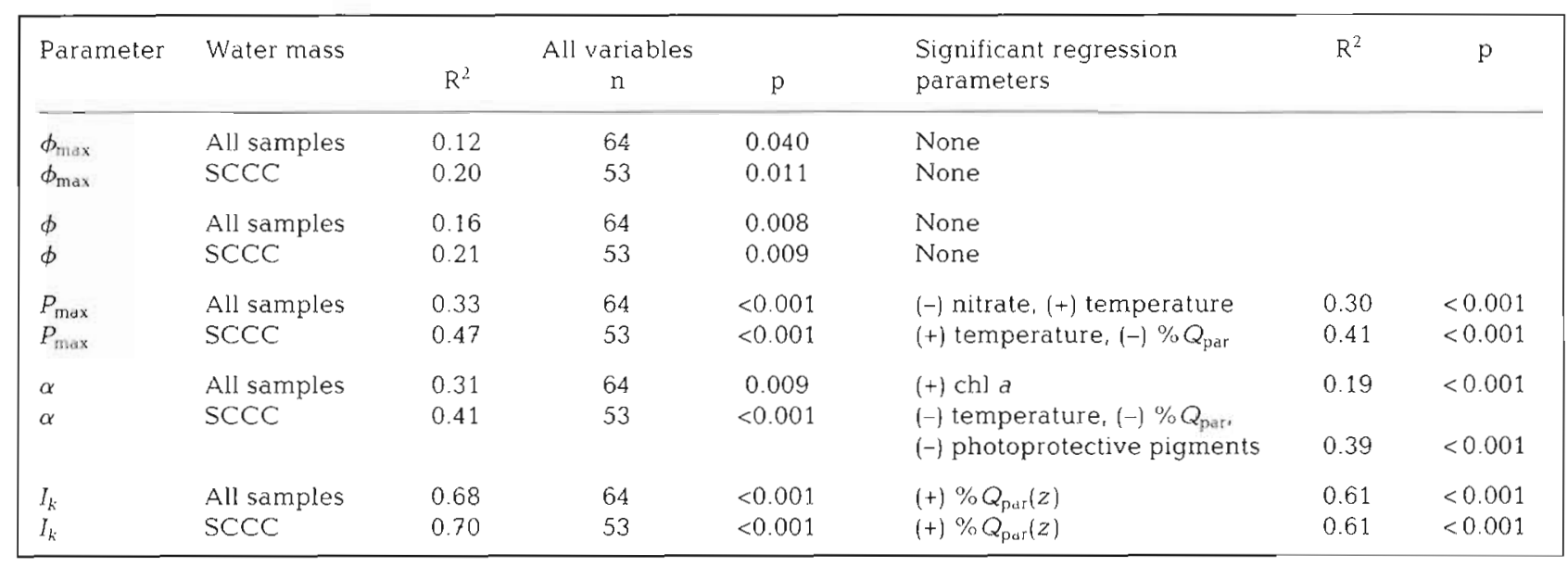

(Table 1). Results of regression analyses indicated that $61 \%$ of the observed variability in $I_{k}$ could be related to variability in $\% Q_{\text {par }}$.

\section{DISCUSSION}

\section{Quantum yield}

Our results lead us to conclude that empirical models based on environmental parameters will have very limited success in predicting instantaneous quantum yield in the SCB. Both $\phi$ and $\phi_{\max }$ were highly variable on time scales of hours to weeks and on spatial scales of less than $150 \mathrm{~km}$. This variability reflected changes in phytoplankton photophysiology as well as community composition within the SCCC. Values of $\phi$ and $\phi_{\text {max }}$ did not routinely increase with light depth. Measured $\phi_{\max }$ values were often less than half the constant values routinely used in bio-optical models. The ratio of assumed versus measured values of $\phi_{\mathrm{max}}$ represents the error by which most models would overestimate rates of carbon fixation. If one assumed that most of the phytoplankton communities in the SCB at the time of Watercolors ' 88 sampling were operating at $\phi_{\max }$ and that $\phi_{\max }$ was a constant with a value equivalent to its theoretical maximum of $0.08 \mathrm{~mol} \mathrm{C} \mathrm{Ein}{ }^{-1}$, then bio-optically predicted estimates of in situ rates of primary production would exceed actual rates by 2 - to 10 -fold depending upon time and location. If one preferred to use a regional average, the mean values for the Watercolors ' 88 quantum yield database for the SCB would be $\phi=0.025 \pm$ $0.018(\mathrm{n}=64)$ and $\phi_{\max }=0.027 \pm 0.019(\mathrm{n}=64)$. The uncertainty introduced by using a regional average quantum yield for a highly variable region of the ocean would not improve the accuracy and time/space resolution of primary productivity within the region. Lastly, the results of our regression analyses indicate it unlikely that the observed variability in $\phi$ and $\phi_{\max }$ could be predicted empirically in the SCB by major physical, optical, chemical and phytoplankton parameters traditionally measured at sea.

These findings may not be surprising to those aware of the many enviromental variables which have a synergistic influence on photosynthetic quantum yield (cf. Prézelin et al. 1991). For instance, variability in $\phi_{\max }$ has been related to nutrient availability (Cleveland et al. 1989), spectral irradiances (Kroon 1991), photoperiods and oscillating light fields (Kroon 1991). biological clock regulation and cell cycle biology (cf. Prézelin 1992), temperature (Tilzer et al. 1985), the photoinhibitory uncoupling of photosynthetic membranes (cf. Powles 1984), and the bright light induction of cellular concentrations of photoprotective carotenoids (Bidigare et al. 1989). When these sources of variability are combined with the species-specific nature of photosynthesis versuses irradiance responses and the time/space dynamics of the different phytoplankton groups comprising the mixed community composition of coastal waters, one might conclude a priori that quantum yield estimates can not be easily predicted for highly variable regions of the oceans.

\section{Photosynthesis-irradiance parameters}

We considered the possibility that while the in situ quantum yield for carbon fixation could not be reliably 
predicted in coastal waters, perhaps the photosynthetic parameters $\left(P_{\max }, \alpha, I_{k}\right)$ which in part reflect the variability in quantum yield could be predicted from knowledge of phytoplankton pigmentation, physical, and optical parameters. If true, then reasonable estimates of quantum yield could be derived from semianalytic models using P-I parameters and knowledge of the amount of quanta absorbed by in situ phytoplankton communities ( $A Q_{p h}$; Eq. 3). Given recent advances in optical instrumentation and approaches to determinations of phytoplankton absorption spectra for natural communities, it appears that reasonable estimates of $A Q_{p h}$ are possible (Bidigare et al. 1992).

During Watercolors '88, chl-specific absorption by phytoplankton varied 2.5 -fold while the quantum yield estimates varied 37 -fold. Given that $>90 \%$ of our samples were light-limited for photosynthesis at the time of sampling (Fig. 7), we were also able to conclude subsurface phytoplankton communities were operating at $\phi_{\text {max }}$ and that much of the observed variability in $\phi$ should be linked to regional variability in $\alpha$ (see Eq. 5). We were unable to reliably and accurately predict the time/space variability in $\alpha$ using a combination of environmental input parameters. Thus, for the time and space scales sampled, there appeared little promise in developing an $\alpha$ dependent approach toward estimates of $\phi_{\max }$. Alternatively, photosynthetic rates might be estimated from knowledge of $P_{\max }$ and $I_{k}$ (Eq. 6). Empirical models for $P_{\max }$ showed little promise but $I_{k}$ appears to be a more predictable parameter. We observed a strong positive correlation between $I_{k}$ and $\% Q_{\text {par }}$, both within the data base presented here and within the larger Watercolors ' 88 database (Baker et al. 1990). Results from the Watercolors ' 88 cruise (cf Prézelin et al. 1991, Schofield et al. 1991, Bidigare et al 1992, Prézelin 1992) and the Fronts ' 85 cruise (Prézelin et al. 1987, Smith et al. 1987, 1989) clearly indicate that our study site in the SCB represents a dynamic range of biotic provinces that change over several time and space scales.

Our findings for the SCB are in contrast to those for the Northern Sargasso Sea (Platt et al. 1992) where $P_{\max }$ and $\alpha$, and thus $I_{k}$, were found to vary little with season. Futhermore the observed variability in the photosynthetic parameters could largely be described by changes in nitrate availability (Platt et al. 1992). It was suggested the constancy of $P_{\max }$ and $\alpha$ in the Sargasso Sea distinguished it as an oceanic biotic province and suggested semi-analytic models of photosynthetic rates appeared promising within this ocean gyre. Within the SCB the empirial trends for $P_{\max } \alpha$, and $\phi$ appeared to contrast those found in laboratory studies where bio-optical paramaters increased with increasing nutrients (Prezelin et al. 1991); however given that laboratory studies represent the physiological state of a sinlge species under controlled conditions it is not surprising that within mixed field communities these laboratory relationships were not observed.

\section{Bio-optical productivity models}

The data presented here supports the view that major improvements in the predictive success of biooptical models will require a more accurate and direct assessment of the in situ variability in quantum yield than presently available in model formulations which assume some fixed behavior for $\phi$. The ability to construct mooring or satellite bio-optical productivity models is dependent on either defining proxy measures for photosynthetic parameters or developing semianalytic models for the P-I parameters based on hydrographic and/or biological information which can be remotely sensed. While semianalytic models appear promising in some oceanic regions (Smith et al. 1991, Platt et al. 1992), their success in dynamic coastal waters will be limited.

We suggest that further improvements for quantum yield-based models should be based on the advancement of techniques which directly assess the photochemical state of a phytoplankton population. Alternative approaches based upon fluorometric analyses show promise. For instance pump-and-probe fluorescence (Falkowski et al. 1986. Falkowski 1992) and Pulse Amplitude Modulated (PAM) fluorescence (Schreiber et al. 1986) measure fluorescence parameters which directly assess the photosynthetic state of a phytoplankton community. The utility of the pump and probe technique in predicting rates of carbon fixation has been recently assessed in the North Pacific (Falkowski et al. 1991). PAM measurements of the quantum yield for open photosystem II reaction centers has been related to $\phi_{\max }$ over a range of nutrient conditions (Henely et al. 1991) and mechanisitic models have been derived which predict photosynthtetic oxygen production from fluorescence parameters alone (Kroon 1991). Another approach might be to estimate $\phi$ from fluorescence excitation spectra. The correspondence between excitation spectra and spectral $\alpha$ has been established for cultured phytoplankton (Neori et al. 1988, Schofield et al. 1990) and for natural phytoplankton communities within the SCB (Nelson unpubl.). The advantage of all these fluorescence measurements is that they are nonintrusive and could be converted for mooring use. This sampling strategy could provide detailed temporal information for optical, physical, and biological parameters (Smith et al. 1991) which in turn would improve our prediction of the environmental regulation of photoadaptation in the ocean. 
Acknowledgements. Research support was provided by the NSF grants OCE 8813728 (R.C.S.), OCE 8800099 (B.B.P.), OCE 8922935 (B.B.P.), and OCE 8913727 (R.R.B.). We gratefully acknowledge Nicolas. P. Boucher's assistance with all P-I measurements and Karen S. Baker for hydrographic and optical data analysis. This Watercolors contribution \#12 was also made possible by the assistance of $\mathrm{H}$. A. Matlick, N. B. Nelson, D. K. Steinberg, E. Stephens, T Coley, D. Menzies, M. Ondrusek, A. Sloan, K. Waters and the crew of the RV 'Melville'. Special thanks are given to N. B. Nelson, B. Kroon, M. Moline, and K. Crocker for thoughtful discussion and suggestions. Comments by 3 anonymous reviewers are acknowledged

\section{LITERATURE CITED}

Baker, K. S., Smith, R. C., Bidigare, R. R., Prézelin, B. B., Lewis, M. R. (1990). A bio-optical model for the prediction of phytoplankton productivity during Fronts '85 and Watercolors '88. EOS 71: 147

Bidigare, R. R., Ondrusek, M. E. (1989). Relationship between quantum yield, particle absorption and primary production in California coastal waters: photosynthetic pigment data report. Dept Oceanography, Texas A\&M Univ.

Bidigare, R. R., Ondrusek, M. E., Morow, M. E., Kiefer, D. A. (1990). In vivo absorption properties of algal pigments. Proc. SPIE Ocean Opt. X. 1302: 290-297

Bidigare, R. R., Prézelin, B. B., Smith, R. C. (1992). Bio-optical models and the problems of scaling. In: Falkowski, P. G., Woodhead, A. D. (eds.) Primary production and biogeochemical cycling in the sea. Plenum Press, New York, p. $175-212$

Bidigare, R. R., Schofield, O., Prézelin, B. B. (1989). Influence of zeaxanthin on quantum yield of photosynthesis of Synechococccus clone WH7803 (DC2). Mar Ecol. Prog. Ser. 56: 177-188

Boucher, N. P., Schofield O., Matlick, H. A, Prezelin, B. B., Smith, R. C., Bidigare, R. R. (1990). Patterns of primary productivity and photosynthesis-irradiance patterns across the Southern California Bight during Watercolors '88 cruise. EOS 71: 146-147

Caceci, M. S., Cacheris, W. P. (1984). Fitting curves to data. Byte 9: 340-362

Cleveland, J. S., Perry, M. J., Kiefer, D. A., Talbot, M. C. (1989). Maximal quantum yield of photosynthesis in the northwestern Sargasso Sea. J. mar. Res. 47: 869-886

Dubinsky, Z., Berman, T., Schanz, F. (1984). Field experiments for in situ measurement of photosynthetic efficiency and quantum yield. J. Plankton Res. 6: 339-349

Eppley, R. W., Holm-Hansen, O. (1986). Primary production in the Southern California Bight. In: Eppley, R. W. (ed.) Plankton dynamics of the Southern California Bight Springer-Verlag, New York, p. 176-209

Falkowski, P. G. (1992). Molecular ecology of phytoplankton photosynthesis. In: Falkowski, P. G., Woodhead, A. D. (eds.) Primary production and biogeochemical cycling in the sea. Plenum Press, New York, p. 47-68

Falkowski, P. G., Kiefer, D. A. (1985). Chlorophyll a fluorescence in phytoplankton: relationship to photosynthesis and biomass. J. Plankton Res. 7: 715-731

Falkowski, P. G., Wyman, K., Ley, A., Mauzerall, D. (1986). Relationship of steady state photosynthesis to fluorescence in eucaryotic algae. Biochim. Biophys. Acta 849 $183-192$

Falkowski, P. G., Ziemann, D., Kolber, Z., Bienfang, P. K. (1991). Role of eddy pumping in enhancing primary pro- duction in the ocean. Nature 352: 55-58

Henely, W. J., Levavasseur, G., Franklin, L. A., Osmond, C. B., Ramus, J. (1991). Photoacclimation and photoinhibition in Ulva rotundata as influenced by nitrogen availibility. Planta 184: 235-243

Jassby, A. D., Platt, T (1976). Mathematical formulation of the relationship between photosynthesis and light for phytoplankton. Limnol. Oceanogr. 21: 540-547

Kiefer, D. A., Chamberlin, W. S., Booth, C. R. (1989). Natural fluorescence of chlorophyll a: relationship to photosynthesis and chlorophyll concentration in the Western Pacific gyre. Limnol. Oceanagr. 34: 868-881

Kiefer, D. A., Mitchell, B. G. (1983). A simple steady state description of phytoplankton growth based on absorption cross-section and quantum efficiency. Limnol. Oceanogr. 28: $770-776$

Kirk, J. T O. (1983). Light and photosynthesis in aquatic ecosystems. Cambridge Univ. Press, Cambridge

Kishino, M., Okamiu, N., Takahashi, M., Ichimura, S. (1986). Light utilization efficiency and quantum yield of phytoplankton in a thermally stratified sea. Limnol. Oceanogr. 31: $557-566$

Kroon, B. (1991). Photosynthesis in algal mass cultures. Ph.D. thesis, Univ. Amsterdam

Laws, E. A. (1991). Photosynthetic quotients, new production and net community production in the open ocean. Deep Sea Res. 38: 143-167

Morel, A., Bricaud, A. (1986). Inherent optical properties of algal cells including picoplankton: theoretical and experimental results. In: Platt, T., Li, W. K. (eds.) Photosynthetic picoplankton. Can. Bull. Fish. Aquat. Sci. 214: $521-559$

Myers, J. (1980). On the algae: thoughts about physiology and measurements of efficiency. In: Falkowski, P. G. (ed.) Primary productivity of the sea. Plenum Press, New York, p. $1-17$

Neori, A., Vernet, M., Holm-Hansen, O., Haxo, F. T. (1988). Comparision of chlorophyll far-red and red fluorescence excitation spectra with photosynthetic oxygen action spectra for photosystem II in algae. Mar. Ecol. Prog. Ser. 44: $297-302$

Platt, T., Gallegos, C. L. (1980). Modeling primary productivity. In: Falkowski, P. G. (ed.) Primary production in the sea. Plenum Press, New York, p. 339-362

Platt, T. Sathyendranath, S., Ulloa, O., Harrison, W. G., Hoepffner, N., Goes, J. (1992). Nutrient control of phytoplankton photosynthesis in the Western North Atlantic. Nature 356: 229-231

Powles, S. B. (1984). Photoinhibition of photosynthesis induced by visible light. A. Rev. Plant Physiol. 35: 15-44

Prézelin, B. B. (1992). Diel periodicity in phytoplankton productivity. Hydrobiologica 238: 1-35

Prézelin, B. B., Bidigare, R. R., Matlick, H. A., Putt, M., Ver Hoven, B. (1987). Diurnal patterns of size-fractionated primary productivity across a coastal front. Mar. Biol. 96: $563-574$

Prézelin, B. B., Glover, H. E. (1991). Variability in time/space estimates of phytoplankton, biomass and productivity in the Sargasso Sea. J. Plankton Res. 13S: 45-67

Prézelin, B. B., Glover, H. E., Ver Hoven, B. M., Steinberg, D. K., Matlick, H. A., Schofield, O., Nelson, N. B., Wyman, M., Campbell, L. (1989). Blue-green light effects on lightlimited rates of photosynthesis: relationship to pigmentation and producitivity estimates from the Sargasso Sea. Mar. Ecol. Prog. Ser. 54: 121-136

Prézelin, B. B., Tilzer, M. M., Schofield, O., Haese, C. (1991). The control of the production process of phytoplankton by the physical structure of the aquatic environment with 
special reference to its optical properties. Aquat. Sci. 53 $136-186$

Priscu, J. C. (1984). In situ quantum yield of phytoplankton in a subalpine lake. J. Plankton Res. 6: 531-542

Schofield, O., Bididgare, R. R., Prézelin, B. B. (1990). Spectral photosynthesis, quantum yield and blue-green light enhancement of productivity rates in the diatom. Chaetoceros gracile and the prymnesiophyte Emiliania huxleyi. Mar. Ecol. Prog. Ser. 64: 175-186

Schofield, O., Prézelin, B. B., Smith, R. C., Stegmann, P. M. Nelson, N. B., Lewis, M. R., Baker, K. S. (1991). Variability in spectral and nonspectral measurements of photosynthetic light utilization efficiencies. Mar. Ecol. Prog. Ser. 78: 253-271

Schreiber, U., Schliwa, U., Bilger, B. (1986). Continuous recording of photochemical and nonphotochemical chlorophyll fluorescence quenching with a new type of modulation fluorometer. Photosyn. Res. 10: 51-62

Sloan, A., Bidigare, R. R. (1990). Spatial variations and temporal evolution of algal pigment distributions in the Southern California Bight. EOS 71:146

Smith, R. C., Bidigare, R. R., Prézelin, B. B., Baker, K. S., Brooks, J. M. (1987). Optical characterization of primary productivity across a coastal front. Mar. Biol. 96 $575-591$

This article was submitted to the editor
Smith, R. C., Booth, C. R., Starr, J. (1984). Oceanographic biooptical profiling system. Appl. Optics 23: 2791-2797

Smith, R. C., Prézelin, B. B., Bidigare, R. R., Baker, K. S (1989). Bio-optical modeling of photosynthetic production. Limnol. Oceanogr. 34: 1526-1546

Smith, R. C., Prézelin, B. B., Bidigare, R. R., Lewis, M. R. Baker, K. S. (1990). Bio-optical; modeling of phytoplankton productivity in the Southern California Bight during times of variable upwelling. EOS 71.121

Smith, R. C., Waters, K. J., Baker, K. S. (1991). Optical variability and pigment biomass in the Sargasso Sea as determined using deep-sea optical mooring data. J. geophys Res. 96: 8665-8684

Tilzer, M. M., Bodungen, B., Smetacek, V. (1985). Lightdependence of phytoplankton photosynthesis in the Antarctic ocean: implications for regulating primary productivity. In: Siegfried, W. R., Condy, P. R., Laws, R. M. (eds.) Antarctic nutrient cycles and food webs. SpringerVerlag, Berlin, p. 60-69

Tyler, J. E. (1975). The in situ quantum efficiency of natural phytoplankton populations. Limnol. Oceanogr. 18: 442-460

Zimmerman, R. C., Soohoo, J. B., Kremer, J. N., D'Argenio, D. Z. (1987). Evaluation of variance approximation techniques for non-linear photosynthesis-irradiance models. Mar. Biol. 95: 209-215

Manuscript first received: September 29, 1992

Revised version accepted: December 14, 1992 